\title{
Transfer of Brightness Discrimination under Unilateral Spreading Depression'
}

\author{
PHILLIP J. BEST ${ }^{2}$ AND MARTIN HAMBURG ${ }^{3}$ \\ University of Michigan, Ann Arbor, Michigan
}

(Received 7 April 1969)

\begin{abstract}
Best, P. J. And M. Hamburg. Transfer of brightness discrimination under unilateral spreading depression. Physiol. Behav. 4 (5) 805-808, 1969.- Rats trained under unilateral cortical spreading depression on a brightness discrimination task for water reinforcement will show little or no transfer when retrained with the contralateral cortex depressed. The current study was performed in order to determine if the degree of transfer can be affected by reinforcement or motivational variables. Rats were trained on a brightness discrimination task to either escape or avoid painful foot shock. The animals trained to escape showed nearly perfect transfer. The animals trained to avoid showed very little transfer of the avoidance response but did transfer the brightness discrimination. It was concluded that in the unilateral spreading depression paradigm the degree of transfer obtained on similar tasks is altered by changing the reinforcement.
\end{abstract}

Cortical spreading depression Interhemispheric transfer Avoidance conditioning Escape conditioning Brightness discrimination

IN THE experimental paradigm in which animals are trained under unilateral spreading depression (UCSD) and retrained with the contralateral cortex depressed, the degree of transfer has been found to depend on many characteristics of the particular task. Transfer is almost complete in some tasks such as passive avoidance $[4,5,6]$, but is normally absent in most active avoidance tasks $[3,6,8,16]$, in operant responding for food reinforcement [12] and in brightness discrimination for water reinforcement [1]. Transfer can be improved by overtraining [9], by simplifying the response [8], by adding more conditioned stimuli [15] and by presenting trials or related experience to the animals in a non-depressed state between initial training and retraining $[1,2,13]$.

One factor that has not been investigated is the degree to which transfer is affected by motivational or reinforcement conditions. Bivens and Ray [1] have found that in a brightness discrimination task very little or no transfer occurs if the reinforcement is water. The present study was performed to determine the degree of transfer found in a brightness discrimination task when the reinforcement is shock escape or avoidance.

\section{METHOD}

\section{Subjects}

Twenty-two male naive Holtzman albino rats $(300-350 \mathrm{~g})$ were maintained individually in home cages with constant access to food and water.

\section{Apparatus}

A Y-maze with electrifiable grid floor served as the apparatus. The start arm was $112 \mathrm{~cm}$ long and the choice arms were $29 \mathrm{~cm}$ long. On each trial, one choice arm was illuminated by a $25-\mathrm{W}$ incandescent bulb located behind the translucent plexiglass end of the arm. A $1.0 \mathrm{~mA}$ constant current scrambled shock was applied to the floor of the start arm and the non-illuminated choice arm. A switch enabled the experimenter to designate either arm as the illuminated safe arm prior to each trial.

\section{Surgery}

The rat was anesthetized with Sodium Pentabarbital and placed in a stereotaxic instrument. Two $5 \mathrm{~mm}$ fenestrae were trephined in the skull on either side of the saggital suture in the parietal bones. Care was taken not to puncture the dura. A $1 \mathrm{~cm}$ long cannula of $6 \mathrm{~mm}$ o.d. and $5 \mathrm{~mm}$ i.d. was placed over each fenestra and fastened to the skull with cranioplastic cement. The cannulae afforded easy access to the dura at time of depression and insured that the depression was unilateral. A small cotton pledget soaked in mineral oil was placed in each cannula. The pledgets were changed daily and the dura inspected. If at any time during surgery or the experiment a tear in the dura or edema was noticed, the rat was discarded.

\section{Procedure}

Daily initial training (IT) sessions began 2-3 days after

\footnotetext{
${ }^{1}$ The authors gratefully acknowledge the technical assistance of Roger W. Cholewiak and Sanford Levinson in the preparation of this study. This research was supported by U.S. Public Health Service Grant. A summary of this study was presented at the May 1968 meeting of the Midwestern Psychological Association.

2Present address: Department of Psychology, Gilmer Hall, University of Virginia, Charlottesville, Virginia 22901.

3Present address: Department of Anatomy, Cornell University Medical College, New York City.
} 
surgery. IT was conducted under UCSD on the same side each day. Prior to each training session, the mineral oil pledget on the side to be depressed was removed. The dura was inspected and cleaned with physiological saline and then dried with cotton. A cotton pledget soaked in $25 \% \mathrm{KCl}$ was placed against the dura. Behavioral tests for the completeness of depression were given 10-15 min later. Placing responses were tested by lightly rubbing a pencil over the back of the limbs. If the limbs contralateral to the depressed hemisphere did not fail to give a placing response the animal was discarded.

Group $1(\mathrm{~N}=13)$ was trained on a shock escape task Group $2(\mathbf{N}=9)$ was trained on shock avoidance. Both groups were trained to run to the illuminated choice arm to escape (or avoid) foot shock. The safe arm was alternated from left to right according to a predetermined random schedule. All rats were placed in the start arm facing away from the choice point. For Group 2 (the avoidance group) shock was withheld for $5 \mathrm{sec}$ after the rat was placed in the start arm, during which time the avoidance response was possible. The rats in Group 1 (the escape group) were placed in the start arm with the current already on. Otherwise, training for the two groups was the same.

On each trial the rat was allowed to run freely until the safe arm was entered. A correct escape discrimination response was recorded if the animal totally entered the illuminated arm without placing any limb in the incorrect arm. The animals in the avoidance group had to learn two separate and somewhat independent tasks: to run immediately when placed on the unelectrified grid floor in order to reach the choice point before
Daily retraining (RT) sessions began the day atter IT was completed and were conducted in the same manner as IT but with the opposite hemisphere depressed. Following RT, 11 rats from Group 1 and 5 rats from Group 2 were given I day of training under bilateral depression.

\section{Histology}

Following RT, the animals were sacrificed and perfused with $10 \%$ formalin and their brains removed to assess the degree of permanent damage due to $\mathrm{KCl}$ application. One transverse section was made through the brain point underlying the center of the cannula. The amount of lesion found was well within the range described by Hamburg, Best, and Cholewiak [7].

RESULTS

About 70 per cent of the animals that started training were discarded due to either damaged dura or failure to become depressed. Discarding most frequently occurred late in training where thickening and hardening of the dura seemed to prevent reliable depression. The dura on the non-depressed hernisphere did not thicken as quickly as the depressed hemisphere, and few animals were discarded early in retraining.

Group 1 showed marked savings in number of trials needed for RT compared with the number of trials for IT. The brightness discrimination escape task trained under unilateral CSD facilitated retraining of the habit with the contralateral hemisphere depressed. Table 1 shows the median and range of scores required for IT and RT by Group 1.

TABLE 1

Median and Range of Trials to Criterion and Number of Days of Training

\begin{tabular}{|c|c|c|c|c|c|c|c|c|}
\hline \multirow[b]{2}{*}{ Group } & & \multirow[b]{2}{*}{ Day 1} & \multicolumn{2}{|c|}{$\begin{array}{l}\text { Initial training } \\
\text { Number of trials }\end{array}$} & \multirow[b]{2}{*}{$\begin{array}{l}\text { Number } \\
\text { of days }\end{array}$} & \multicolumn{3}{|c|}{$\begin{array}{c}\text { Retraining } \\
\text { Number of trials }\end{array}$} \\
\hline & & & Day 2 & Last day & & Day 1 & Last day & $\begin{array}{l}\text { Number } \\
\text { of days }\end{array}$ \\
\hline 1 & Escape & $\begin{array}{l}50^{*} \\
\left(28-50^{*}\right)\end{array}$ & $\begin{array}{l}12 \\
\left(10-50^{*}\right)\end{array}$ & $\begin{array}{l}11 \\
(10-14)\end{array}$ & $\begin{array}{l}4 \\
(3-8)\end{array}$ & $\begin{array}{l}10 \\
\left(10-50^{*}\right)\end{array}$ & $\begin{array}{l}10 \\
(10)\end{array}$ & $\begin{array}{l}2 \\
(2-5)\end{array}$ \\
\hline \multirow[t]{3}{*}{2} & $\begin{array}{l}\text { Brightness } \\
\text { Discrimination }\end{array}$ & $\begin{array}{l}50^{*} \\
\left(27-50^{*}\right)\end{array}$ & $\begin{array}{l}24 \\
\left(14-50^{*}\right)\end{array}$ & $\begin{array}{l}10 \\
(10-14)\end{array}$ & $\begin{array}{l}4 \\
(3-6)\end{array}$ & $\begin{array}{l}14 \\
(10-28)\end{array}$ & $\begin{array}{l}10 \\
(10)\end{array}$ & $\begin{array}{l}2 \\
(2-4)\end{array}$ \\
\hline & Avoidance & $\begin{array}{l}50^{*} \\
\left(28-50^{*}\right)\end{array}$ & $\begin{array}{l}38 \\
\left(14-50^{*}\right)\end{array}$ & $\begin{array}{l}12 \\
(10-20)\end{array}$ & $\begin{array}{l}5 \\
(4-7)\end{array}$ & $\begin{array}{l}49 \\
\left(17-50^{*}\right)\end{array}$ & $\begin{array}{l}13 \\
(10-20)\end{array}$ & $\begin{array}{l}4 \\
(3-6)\end{array}$ \\
\hline & $\begin{array}{l}\text { Avoidance } \\
\text { Minus } \\
\text { Discrimination }\end{array}$ & $\begin{array}{l}0 \\
(0-22)\end{array}$ & $\begin{array}{l}2 \\
(0-16)\end{array}$ & $\begin{array}{l}2 \\
(0-9)\end{array}$ & $\begin{array}{l}0 \\
(0-4)\end{array}$ & $\begin{array}{l}31 \\
(3-40)\end{array}$ & $\begin{array}{l}3 \\
(0-10)\end{array}$ & $\begin{array}{l}2 \\
(0-4)\end{array}$ \\
\hline
\end{tabular}

*Animals that did not reach the daily criterion were run for a maximum of 50 trials on that day.

shock onset, and the brightness discrimination. Therefore, two records were kept of these animals' performance. A correct escape discrimination response was recorded even if the animal did not avoid the shock, but a correct avoidance response was recorded only if the animal made the correct discrimination response before shock onset. If the animal did not enter the safe arm within $2 \mathrm{~min}$ it was guided into the correct arm. The animal was allowed to remain in the safe arm for $1 \mathrm{~min}$ prior to being placed in the start arm for the next trial. Each IT session continued until 9 out of 10 correct escape (or avoidance) trials were recorded, or a maximum of 50 trials was reached. Daily IT sessions continued until the animal reached the criterion of 9 out of 10 correct responses within 20 trials on two consecutive days.
By a sign test, the median number of trials to criteria on Day 1 of RT was significantly lower than Day 1 of IT ( $p$ $0.005)$, and Day 2 of IT $(p<0.04)$, but did not differ from the last day of IT ( $p=0.35$ ). Only 3 out of the 13 rats in Group 1 did not reach criterion within the first 20 trials on Day 1 of RT.

Group 2 showed a deficit in avoidance performance from the last day of IT to the first day of RT. However, some saving in the avoidance response was evident. The median number of trials required to learn to avoid the shock as well as the number of trials required to learn the brightness discrimination, irrespective of avoidance, appear in Table 1. By the sign test, the number of trials to reach criterion on Day 1 of RT was significantly lower than on Day 1 of IT $(p<0.03)$, was higher but not significantly different from Day 2 of IT 
( $p=0.11)$ and was significantly higher than the last day of IT $(p<0.002)$.

Considering only the brightness discrimination scores of Group 2, the number of trials to reach criterion on Day 1 of RT was significantly lower than on Day 1 of IT $(p<0.002)$ and Day 2 of IT $(p<0.02)$ but not different from the last day of IT $(p=0.50)$. These differences are similar to the data of Group 1.

In order to more thoroughly analyze the different results obtained with the avoidance and brightness discrimination scores the difference in these scores was tabulated for each animal. The avoidance minus discrimination scores in the bottom row of Table 1 indicate the number of trials needed to learn the avoidance task after the brightness discrimination had been learned. The avoidance minus discrimination score on Day 1 of RT was significantly greater than the score for the first, second and last day of IT (all $p$ 's $<0.05$ ).

After RT, under bilateral CSD all rats in Group $1(\mathrm{~N}=11)$ reached criterion within the first 11 trials (i.e., 0 or 1 precriterion trial) with median latencies of 2 to $4 \mathrm{sec}$. Three of the 5 rats in Group 2 did not reach avoidance criterion within 50 trials when under bilateral CSD. The other 2 required 27 and 29 trials. Four of the rats in Group 2 reached criterion on the brightness discrimination in 10 or 11 trials; 1 rat required 23 trials.

\section{DISCUSSION}

The results indicate complete transfer of a brightness discrimination habit under both shock escape and avoidance, and a somewhat lesser degree of transfer of an avoidance response. Previous studies have found no transfer of shock avoidance in the UCSD paradigm $[3,6,8,16]$. The slight transfer of avoidance found here can be accounted for by the fact that during IT the avoidance animals had to learn both the brightness discrimination and the avoidance response, but during RT they did not have to relearn the brightness discrimination and therefore were learning a simpler task. During IT the animals in Group 2 usually failed to avoid the shock because they entered the incorrect choice arm. However, during RT the animals initially waited in the start arm for the shock onset and then ran directly to the correct arm. During IT the animals learned to successfully avoid immediately or within a few trials of learning the brightness discrim- ination, but during RT a significantly greater number of trials was needed.

Bivens and Ray [1] found no transfer in a similar brightness discrimination under water reinforcement. The difference between their results and those reported here can be attributed to differences between aversive and appetitive reinforcement. Sechzer [14] found that cats with optic chiasm and corpus callosum transections showed interocular transfer of pattern discrimination under shock avoidance, but did not show transfer of the same pattern discrimination under food reinforcement. Care must be taken in comparing the UCSD experiments in rats with the split brain experiments in cats, since split brain cats normally transfer avoidance responses [14] and brightness discrimination under food reinforcement [10], but rats under UCSD transfer neither of these responses $[1,3,6$, $8,16]$.

The transfer of the brightness discrimination under unilateral CSD and the near perfect saving under later bilateral CSD indicates that the elaboration and the storage of this habit must be accomplished in brain areas that are not rendered dysfunctional under CSD.

The fact that two of the rats in Group 2 were capable of performing the avoidance task under bilateral CSD is not contradictory to the findings that rats under bilateral CSD usually cannot learn avoidance responses [15]. In the current study the animals were not required to learn a new habit but were required to relearn a task that they had previously performed under slightly different conditions. Although the rats in Group 2 did not show an impressive degree of transfer, the fact that two animals showed savings under bilateral CSD indicates that unilateral training of an avoidance response can occur to some degree in brain areas that are not rendered dysfunctional by CSD.

There results demonstrate possible effects of task and/or reinforcement specificity on transfer of a unilaterally trained habit. Certain brain areas, more or less effected by the CSD, may serve different roles in the learning or performance of specific habits. The mechanism by which task specificity effects the behavior observed in a testing situation involving CSD is uncertain. However, the present findings when considered with the findings of Bivens and Ray [1] and Sechzer [10] indicate that the plastic changes in the central nervous system that accompany learning must occur at different levels for the same task learned under different reinforcement conditions.

\section{REFERENCES}

1. Bivens, L. and O. S. Ray. Memory trace disruption by cortical spreading depression. Psychol. Rep. 17: 175-178, 1965.

2. Bureš, J. Reversible decortication and behavior. In: Conference on the central nervous system and behavior, edited by M. A. B. Brazier, New York: Josiah Macy, Jr., Foundation, 1959, Pp. 207-248.

3. Bureš, $J$. and $O$. Burešová. The use of Leao's spreading depression in the study of interhemispheric transfer of memory traces. J. comp. physiol. Psychol. 53: 558-563, 1960.

4. Bureš, J. and O. Burešová. Interhemispheric transfer of extinction of the passive avoidance reaction in rats. J. comp. physiol. Psychol. 62: 459-461, 1966.

5. Bureš, J., O. Burešová and E. Fifkova. Interhemispheric transfer of a passive avoidance reaction. J. comp. physiol. Psychol. 57: 326-330, 1964.

6. Carlson, K. R. Cortical spreading depression and subcortical memory storage. J. comp. physiol. Psychol. 64: 422-430, 1967.
7. Hamburg, M. D., P. J. Best and R. W. Cholewiak. Cortical lesions resulting from chemically induced spreading depression. J. comp. physiol. Psychol. 66: 492-494,1968.

8. Kukleta, M. Learning in functionally decorticate state and its transfer to normal state. J. comp. physiol. Psychol. 62: 498-500, 1966.

9. Kukleta, $M$. The use of unilateral cortical spreading depression in the study of subcortical storage of memory traces in rats. Physiol. Behav. 2: 301-304, 1967.

10. Meikle, T, and J. Sechzer. Interocular transfer of brightness discrimination in "split brain" cats. Science 132: 734-736, 1960.

11. Ray, O. and G. Emiley. Interhemispheric transfer of learning. Life Sci. 4: 271-279, 1965.

12. Russell, 1. S. and S. Ochs. Localization of a memory trace in one cortical hemisphere and transfer to the other hemisphere. Brain 86: 37-54, 1963. 
13. Schneider, A. M. and M. Hamburg. Interhemispheric transfer with spreading depression: A memory transfer or stimulus generalization phenomenon? J. comp. physiol. Psychol. 62: $133-136,1966$.

14. Sechzer, J. Successful interocular transfer of pattern discrimination in "split brain" cats with shock avoidance motivation. J. comp. physiol. Psychol. 58: 76-83, 1964.
15. Thompson, R. W. and L. A. Hjelle. Effects of stinulus and response complexity of learning under bilateral spreading depression. J. comp. physiol. Psychol. 59: 122-124, 1965.

16. Travis, R. P. and D. L. Sparks. The influence of unilateral and bilateral spreading depression during learning upon subsequent relearning. $J$. comp. physiol, puchol. 56: 56.59, 1963. 